University of Nebraska - Lincoln

DigitalCommons@University of Nebraska - Lincoln

Educational Psychology Papers and

Publications

Educational Psychology, Department of

January 2003

\title{
Childhood peer relationships in context
}

Susan M. Sheridan

University of Nebraska-Lincoln, ssheridan2@unl.edu

Eric S. Buhs

University of Nebraska-Lincoln, ebuhs2@unl.edu

Emily D. Warnes

University of Nebraska-Lincoln

Follow this and additional works at: https://digitalcommons.unl.edu/edpsychpapers

Part of the Educational Psychology Commons

Sheridan, Susan M.; Buhs, Eric S.; and Warnes, Emily D., "Childhood peer relationships in context" (2003). Educational Psychology Papers and Publications. 21.

https://digitalcommons.unl.edu/edpsychpapers/21

This Article is brought to you for free and open access by the Educational Psychology, Department of at DigitalCommons@University of Nebraska - Lincoln. It has been accepted for inclusion in Educational Psychology Papers and Publications by an authorized administrator of DigitalCommons@University of Nebraska - Lincoln. 
Published in Journal of School Psychology 41 (2003), pp. 285-292. Copyright (C) 2003 Society for the Study of School Psychology. Published by Elsevier Science Ltd. Used by permission. doi:10.1016/S0022-4405(03)00049-9

Submitted and accepted January 21, 2003.

COMMENTARY

\title{
Childhood peer relationships in context
}

\author{
Susan M. Sheridan*, Eric S. Buhs, Emily D. Warnes \\ Department of Educational Psychology, University of Nebraska-Lincoln, \\ 239 Teachers College Hall, Lincoln, NE 68588-0345, USA
}

Gifford-Smith and Brownell (2003) have provided an extensive critical review of the current state of the art in peer relations research. Their thorough review of the basic research in these areas clearly illustrates the complexity of the task of understanding these aspects of children's social development and how they navigate the interrelated relational ecologies. Our purpose is to extend the discussion by suggesting implications for intervention work and related research.

\section{A contextual perspective for bridging peer relations research and intervention}

Among the many issues raised by Gifford-Smith and Brownell, the importance of recognizing the role that context plays in children's peer relationships is perhaps most striking. This tenet is so essential that it serves as an organizing principle guiding our discussion of peer relationship interventions with children. As such, we propose that a contextual perspective provides a useful heuristic. Within this perspective, children's peer relationships and their social skillfulness are considered in relation to specific social contexts within which they participate. The social norms and demands of these contexts are central to understanding the roles children's peer relationships play in adjustment. They are also central in assessing children's social skillfulness within different settings and relationship types.

Elements of context relevance theory (Sailor, Goetz, Anderson, Hunt, \& Gee, 1988) highlight the importance of context in designing effective social skills interventions. According to this theory, social skills should be acquired in the context in which they are used (e.g., the classroom, playground, neighborhood) and should be adaptable to various social situations (e.g., different relationship types). Thus, the interaction of context, children's social skillfulness, and the type of peer relationship targeted will be central elements in conceptualizing effective interventions.

* Corresponding author. Email: ssheridan2@unl.edu (S.M. Sheridan). 


\section{Context}

Clearly, the perceptions, cognitions, and behaviors most important for children to be considered socially skilled are not universal; they vary depending on a plethora of considerations relevant to one's social-developmental-ecological context. We have chosen to define context broadly and include interrelated conditions residing (a) within the immediate setting (i.e., such as neighborhood, school, home, community), and (b) within different types of interpersonal relationships (i.e., such as the different types of peer relationships, family relationships, and school-based social relationships). This definition, influenced by ecological-developmental theory (Bronfenbrenner, 1977), recognizes that the child exists within multiple intersecting and overlapping systems. The multiple ecological systems determine which behaviors are considered adaptive, functional, and nonnative. None of the levels (child, setting, relationships) can be considered in isolation. They are truly interrelated in determining the effectiveness of social actions and behaviors.

Gifford-Smith and Brownell provided many referents to the importance of context as they discussed differences in the form, quality, and functions of peer relationships. We stress that the attributes of different contexts and, especially, children's awareness of these dynamic attributes often determine the degree to which children skillfully navigate their social world. Thus, we believe that children's social skillfulness within a particular context, as well as across different contexts, contributes to the adaptive or maladaptive characteristics of their peer relationships in those settings.

\section{Social skillfulness}

Our conception of social skillfulness addresses the interaction of a child's social behaviors (including cognitive events) and context. As suggested previously, the effectiveness of the behaviors used by a child is in large part determined by the situations within which they are performed. To be socially skillful, children must (a) master a range of social behaviors that can be accessed across a variety of social situations and (b) learn to relate in a way that is acceptable to others in their social worlds (Sheridan \& Walker, 1999). More specifically, social skillfulness concerns behaviors or skills manifested flexibly and adaptively, and considered by meaningful others to be appropriate and acceptable within various environmental conditions. Certainly, the perceptions of others and degree to which peers find behaviors acceptable contribute to the formation and maintenance of adaptive peer relationships. Children who lack a developmentally appropriate understanding of the differing skill demands across contexts will be less likely to successfully meet the adaptive tasks within different contexts and types of relationships.

\section{Peer relationships}

Gifford-Smith and Brownell reported that peer relations research has made some headway in beginning to define which social skills might be relevant to forming and maintaining different relationship types (i.e., skills valuable for friendships vs. those relevant 
to peer acceptance). However, little attention has been directed at investigating the commonalities and differences in skill requirements for these relationships across contexts. The adaptive skills needed for maintaining adaptive or supportive friendships within a classroom context may differ significantly from those required in a neighborhood setting. Intervention research to date has not addressed in significant detail the question of how children understand the changes in relationship processes and provisions across different contexts. Given findings from intervention research indicating that social skills interventions are not generally effective when taught in isolation from a natural context, a better understanding of differences in children's relationships and in their perceptions of relationships across the various contexts in which they participate is central for the goal of creating more effective interventions.

\section{Assessment and intervention implications}

Assessment and intervention must consider aspects of the social settings in which children participate as they relate to social skills and peer relationships. Below we will explore implications at the level of the child, the social setting, and others in the child's interpersonal social network. Assessment and intervention implications will be discussed in tandem. Given space limitations, only factors most relevant to our contextual framework will be highlighted. Interested readers are referred to Sheridan and Walker (1999) and Ladd, Buhs, and Troop (2002) for more extensive attention.

From a contextual perspective, intervention work must include adults and others who control the social environments within which children exist and function. Research is clear that skills and behaviors taught in isolation or in decontextualized conditions do not generalize to natural settings (DuPaul \& Eckert, 1994) and have little effect on the formation of positive peer perceptions and relations (Kavale, Mathur, Forness, Rutherford, \& Quinn, 1997). In light of the importance of social-cognitive variables contributing to a child's social performance, it seems particularly essential to address social behaviors and skills within settings that give them meaning (Haring, 1992). Ecologically based assessment/intervention models that address the child, setting, and interpersonal considerations appear promising.

\section{Assessment and intervention: individual child considerations}

Child-level assessment and intervention should include cognitive characteristics such as the child's (a) ability to "read" the social cues within his/her environment and group, (b) interpretations of situations, and (c) understanding of group norms and expectations. Likewise, consideration of a child's individual developmental level is important. As discussed by Gifford-Smith and Brownell, developmental factors certainly affect the types of behaviors and cognitions demonstrated by children and, consequently, the nature of their peer relationships. Developmental constructs such as emotional regulation and shared understanding (Guralnick, 1993; Guralnick \& Neville, 1997) are important for determining the types of social behaviors that are normative for children at a particular developmental level and highlighting areas for intervention. Whereas recognition of these variables and 
their influence on a child's behaviors have been emerging in the literature for decades, no clear evidence-based intervention method for addressing these cognitive and developmental variables has emerged.

Alternatively, more research has addressed assessment and intervention at the behavioral level, such as a child's ability to perform important entry, maintenance, and conflict resolution behaviors and demonstration of prosocial behaviors. However, the competence with which a child can flexibly moderate his/her behavior based on a particular situation (i.e., context) has not received attention. Clearly, the link between a child's skills and his/ her adaptive use of these skills in multiple settings and situations remains essential to a child's successful social functioning.

\section{Assessment and intervention: setting considerations}

In terms of social intervention, context or setting considerations involve those that address complex characteristics of the environment and the manner in which they contribute to relationship formation. In this arena, assessment/intervention may include an appraisal of the physical arrangement of a social ecology (e.g., desks in a classroom or other arrangements that facilitate or hinder interaction; the presence of toys, games, or equipment) around which interactions can occur. Clearly. the physical or concrete dimensions of a setting may produce differential impact based on developmental characteristics such as age. However, physical features continue to effect relationships across developmental levels (e.g., access to cars and recreational opportunities in adolescence).

Along with physical and concrete features of a social setting, social task demands within the environment are important to understand. For example, in some social contexts, tasks require cooperativeness or team play to be successful; in others, independent or competitive behaviors are required. From this perspective, objectives of assessment and intervention include (a) determining the expectations, demands, and norms for behavior in the criterion environment; (b) determining conditions in the environment that precipitate, reinforce, discourage, or extinguish specific behaviors: (c) analyzing functions that behaviors serve in naturalistic settings; and (d) identifying behaviors and skills that have practical and meaningful significance in natural settings (i.e., are socially valid) (Sheridan \& Walker, 1999).

Assessment and intervention: interpersonal considerations

Assessment and intervention of interpersonal considerations address the interpersonal relationships and influences in a child's social world, including those that can facilitate adaptive peer relationships. At this level, assessment and intervention should include (a) appraisal of the relevant peer group; (b) defining characteristics of different types of peer relationships; and (c) the use of others (including adults) to teach, reinforce, and assist in the generalization of effective social skills in relevant social milieus.

To understand how certain actions and overtures will be interpreted, interventionists must be concerned with the manner in which peers perceive others within different peer 
relationships. As touched upon by Gifford-Smith and Brownell, significant differences exist in the interaction patterns and behaviors deemed acceptable and desirable within different social networks. Understanding the social networks for a particular child can suggest critical targets for intervention. Consistent with our framework, it is expected that behaviors perceived as appropriate or acceptable may be contextually bound and developmentally specific. To facilitate the understanding of the interpersonal influences on peer relationships, interventionists should assess behaviors that are reinforced by others in the environment, including adults. It is possible that the identification and teaching of such behaviors can lead to naturally reinforcing conditions for a child through processes such as behavioral entrapment (McConnell, 1987). For example, smiling and offering to share a toy may lead to a mutually enjoyable play interaction, thereby "trapping" these behaviors and encouraging their use in future similar situations. It is also noteworthy to recognize that behaviors reinforced by others may vary depending on the source. That is, parents, teachers, and peers may support or reinforce different behaviors based on what they perceive to be important for different peer relationships and types of social skillfulness.

A combination of direct and indirect intervention is necessary when addressing a child's social performance. Such interventions may teach a child's behavioral patterns that are relevant within criterion settings (direct intervention), utilize natural agents such as parents and teachers (indirect intervention), all with attention to what is salient and important within the social milieu within which the child ultimately must function (i.e., have criterion and predictive validity). Parents and other adults who control social conditions are particularly important in the development and implementation of naturalistic (i.e., relevant, contextualized) social interventions. Parents play an important role in supporting their child's friendships through selecting neighborhoods and schools and providing opportunities for peer interactions. Furthermore, the manner in and degree to which caregivers work in tandem with each other in support of the child can in part determine his/her development of social competence. Specifically, multisystemic interventions can strive to place parents and other caregivers (e.g., teachers, day-care providers) in unique collaborative positions, working conjointly to promote continuity and consistency in social intervention approaches. Adults (including parents, teachers, and other care providers) can model prosocial behaviors, prompt adaptive interpretations, coach appropriate responses in vivo, and reinforce all attempts at appropriate social interactions.

\section{Research implications}

The complexity of the interrelated constructs of context, social skillfulness, and peer relationships makes intervention research thorny. Clearly, sophisticated research designs are necessary to incorporate the complex and interdependent variables that determine the adaptive or maladaptive qualities of peer relationships and the social skillfulness children need to successfully manage multiple relationships across contexts. Mixed method designs that incorporate the multivariate, nested, idiosyncratic, and qualitative aspects of peer relationships will be necessary to examine these questions. As intervention studies incorporate more advanced methods and more varied aspects of contextual and relational 
constructs, several salient questions need to be addressed - we conclude by addressing some of the more prominent that have been raised by investigators and practitioners.

What are the relevant and valid outcomes that are most important/relevant for a child's social competence?

The majority of intervention research studies have focused on discrete prosocial behaviors or "social skills" as outcomes that are most critical; however, little is known about the specific influence these have on the formation and maintenance of friendships, friendship networks, or peer acceptance. Social-cognitive variables addressing one's perceptions and interpretations of social situations and contexts, the ability to "read" social cues, and attributions for social outcomes may also be important; however, the specific manner in which these influence behavior (and are alterable through intervention) is unknown.

Other possible targets for intervention include the development, maintenance, and stability of dyadic friendships. For example, participation in a close friendship, number of reciprocal friends, durations of friendships, and other qualitative features of friend-ship may be important variables to investigate (Ladd et al., 2002). Very little is known about how to successfully intervene at this level. If it is the friendship relationship that is viewed as critical to one's success in a given setting (i.e., predictive of positive life outcomes), it is essential that interventionists begin to understand how to impact this criterion at different developmental levels to promote more supportive relationships over time.

\section{What are important behaviors that define social skillfulness and predict adaptive peer relationships?}

Clearly, the behaviors and skills most important in determining social skillfulness and effective relationships vary based on a child's personal characteristics (e.g., age, gender, developmental level) and features of the social ecology (e.g., peer group, goals, task demands). A central question within our contextual perspective concerns how such skills can be identified with appropriate developmental sensitivity and taught within a contextual framework.

What are effective ways to teach children adaptive social-cognitive strategies that generalize to behavior?

Given the research illustrating differences in children's social-cognitive characteristics and their relationship to behavior, it is assumed that some attention to social-cognitive variables will be important. However, researchers have not identified what it is that should be taught, and how, at what age, and in what setting these strategies should be taught. Furthermore, the relationship between cognitive training and generalized skill use is far from understood. The degree to which such training assists a child to engage in behaviors that are acceptable and appropriate within particular peer relationships and contexts determines the efficacy of the intervention. 
What is the most effective way of teaching children in naturalistic social situations?

Intervention research has demonstrated repeatedly that "pull out" social skills training approaches, wherein interventions occur in decontextualized settings such as artificial training groups, uniformly fail to generalize to "real world" conditions (DuPaul \& Eckert, 1994). However, researchers have been unsuccessful in identifying ways to promote socially valid and meaningful skill use outside of training programs. Suggestions for training in "real world" contexts have been proposed (Sheridan, Hungelmann, \& Maughan, 1999) but inadequately tested to date. Of central importance seems to be how interventionists can utilize others (e.g., parents, teachers, peers) in the natural environment to facilitate the development of positive social relationships.

Strengthening the link between natural contexts and interventions, including integrating social supports from adults and peers across contexts, will help intervention efforts gain ecological validity and facilitate children's development of contextual awareness and relevant adaptive behaviors. Children who become more aware of the demands of different types of peer relationships within and across diverse contexts are likely to become more skilled at forming and maintaining supportive relationships.

\section{Acknowledgements}

Preparation of this article was supported in part by a federal grant awarded to the first author by the U.S. Department of Education (H325D990010). The opinions expressed herein are those of the authors and do not reflect positions of the granting agency.

\section{References}

Bronfenbrenner, U. (1979). The ecology of human development. Cambridge, MA: Harvard Univ. Press. DuPaul, G. J., \& Eckert, T. L. (1994). The effects of social skills curricula: Now you see them, now you don't. School Psychology Quarterly, 9, 113-132.

Gifford-Smith, M. E., \& Brownell, C. A. (2003). Childhood peer relationships: Social acceptance, friendships, and peer networks. Journal of School Psychology, 41, 235-284.

Guralnick, M. J. (1993). Developmentally appropriate practice in the assessment and intervention of children's peer relations. Topics in Early Childhood Special Education, 13, 344-371.

Guralnick, M. J., \& Neville, B. (1997). Designing early intervention programs to promote children's social competence. In M. J. Guralnick (Ed.), The effectiveness of early intervention (pp. 579610). Baltimore, MD: Paul H. Brookes Publishing.

Haring, T. G. (1992). The context of social competence: Relations, relationships, and generalization. In S. L. Odom, S. R. McConnell, \& M. A. McEvoy (Eds.), Social competence of young children with disabilities: Issues and strategies for intervention (pp. 307-320). Baltimore, MD: Brookes.

Kavale, K. A., Mathur, S. R., Forness, S. R., Rutherford, R. B., \& Quinn, M. M. (1997). Effectiveness of social skills training for students with behavior disorders: A meta-analysis. Advances in Learning and Behavioral Disabilities, 11, 1-26. 
Ladd, G. W., Buhs, E. S., \& Troop, W. (2002). Children's interpersonal skills and relationships in school settings: Adaptive significance and implications for school-based prevention and intervention programs. In P. K. Smith, \& C. H. Hart (Eds.), Blackwell handbook of childhood social development (pp. 394--415). Malden, MA: Blackwell Publishers.

McConnell, S. R. (1987). Entrapment effects and the generalization and maintenance of social skills training for elementary school students with behavioral disorders. Behavioral Disorders, 12, 252-263.

Sailor, W., Goetz, L., Anderson, J., Hunt, P., \& Gee, K. (1988). Research on community intensive instruction as a model for building functional, generalized skills. In R. H. Horner, G. Dunlap, \& R. L. Koegel (Eds.), Generalization and maintenance: Life-style changes in applied settings (pp. 67-98). Baltimore: Paul H. Brookes.

Sheridan, S. M., Hungelmann, A., \& Maughan, D. P. (1999). A contextualized framework for social skills assessment, intervention, and generalization. School Psychology Review, 28, 84-103.

Sheridan, S. M., \& Walker, D. (1999). Social skills in context: Considerations for assessment, intervention, and generalization. In C. R. Reynolds, \& T. B. Gutkin (Eds.), The handbook of school psychology (3rd ed.) (pp. 686-708). New York: Wiley. 